\title{
A TECNOLOGIA COMO FERRAMENTA DE COMUNICAÇÃO ENTRE OS PROFESSORES: UMA REFLEXÃO SOBRE A CIDADANIA
}

\author{
Bruna Silva dos Santos ${ }^{1}$ \\ Sirlei Nádia Schirmer ${ }^{2}$ \\ Joice Rejane Pardo Maurell ${ }^{3}$ \\ Flávia Cardoso Pereira dos Santos ${ }^{4}$
}

\begin{abstract}
RESUMO
O presente trabalho apresenta o relato e a análise das vivências desencadeadas durante a construção e execução do "Projeto de Ação na Escola - PAE", que foi aplicado junto ao grupo de professores de uma escola no município de Gravataí/RS. Para a realização desta prática, foi eleita a metodologia de Unidade de Aprendizagem, que desenvolveu-se presencialmente e a distância. Por meio deste, objetivou-se estabelecer o liame interdisciplinar entre as temáticas: Tecnologias da Informação e da Comunicação (TICs), educação e cidadania. A metodologia de pesquisa utilizada foi a documental e bibliográfica, com abordagem qualitativa, especialmente para a realização da análise dos dados. O referencial teórico teve seu aporte em autores como Demo, Libâneo, Moran, entre outros. A partir dos resultados, depreende-se que os diálogos mediados pelas tecnologias digitais móveis, nesse caso, foram eficazes à realização de reflexões de qualidade, proporcionando o pensar dos docentes a respeito das potencialidades da inserção das TICs na educação.

PALAVRAS - CHAVE: TECNOLOGIAS DA INFORMAÇÃO E DA COMUNICAÇÃO. EDUCAÇÃO. CIDADANIA.
\end{abstract}

\section{THE TECHNOLOGY AS A COMMUNICATION TOOL AMONG TEACHERS: A REFLECTION ON CITIZENSHIP}

\begin{abstract}
The following text intends to present the report and analysis of the unleashed experiences during the process of construction and execution of the project called "Projeto de Ação na Escola - PAE". The project was developed in a group of teachers from a school in the city of Gravataí/RS. It was chosen the methodology of learning units to execute the practice in person and distance. The objective was to establish the interdisciplinary relation between the following topics: Information and Communication Technologies (ICTs), education and citizenship. The analysis of the data was developed with the qualitative methodology to reach the objectives. In terms of the theoretical approach, it was used authors such as Demo, Libâneo, Moran, and others. Given the results analysis, it concludes that the dialogues mediated by the digital and mobile technologies are effective to the realization of high quality reflections, providing the teachers thinking about the potentialities of ICTs insertion in the education.
\end{abstract}

KEYWORDS: INFORMATION AND COMMUNICATION TECHNOLOGIES. EDUCATION. CITIZENSHIP.

\footnotetext{
${ }^{1}$ Mestranda em Informática na Educação, MPIE, IFRS, campus Porto Alegre - Especialista em Tecnologia da Informação e Comunicação na Educação - TIC-Edu, FURG. Email: bruna.santos@ @osorio.ifrs.edu.br

${ }^{2}$ Doutoranda em Educação em Ciências, PPGEC, FURG - professora-orientadora, TIC-Edu, FURG. Email: snschirmer@gmail.com

${ }^{3}$ Doutoranda em Educação em Ciências, PPGEC, FURG - professora-orientadora, TIC-Edu, FURG. Email: joicerejane@furg.br

4 Mestre em Modelagem Computacional, FURG - professora-orientadora, TIC-Edu, FURG. Email: faflasan@gmail.com
} 


\section{INTRODUÇÃO}

Por meio deste artigo serão apresentados o relato e a análise das vivências desencadeadas durante a construção e execução do "Projeto de Ação na Escola - PAE", no curso Pós-Graduação em Tecnologias da Informação e Comunicação na Educação (TIC-Edu) - FURG, em nível de especialização, na modalidade EAD. O tema deste estudo origina-se da inquietação: "Como a inserção das Tecnologias da Informação e Comunicação (TICs) na atividade docente pode fomentar a reflexão sobre a cidadania?"

Para tanto, foi realizada a aplicação do PAE com um grupo de professores de uma escola municipal de Gravataí/RS. Ocorreram encontros em momentos presenciais e a distância e foi eleito como recurso tecnológico mediador o aplicativo WhatsApp, por meio de um grupo de professores voluntários. A escolha desta tecnologia funda-se no fato de tratar-se de uma das ferramentas de comunicação instantânea mais utilizada na atualidade.

No tocante ao planejamento, as ações do PAE nortearam-se pela metodologia de Unidade de Aprendizagem (UA) por reconhecer o seu potencial de protagonizar o desempenho dos integrantes do grupo e pelo estabelecimento de espaços de democratização do diálogo. A pesquisa desenvolveu-se pela metodologia documental e bibliográfica, por um viés qualitativo. No que tangue à análise dos dados, reforça-se que esta foi realizada com base na metodologia qualitativa, por ter foco no caráter subjetivo e prezar pela singularidade do objeto de estudo. Em relação à coleta das informações, foi utilizado o espaço virtual de registro do próprio grupo de WhatsApp, que armazenou e concentrou a comunicação entre os participantes.

Nesse contexto, objetivou-se estabelecer o liame interdisciplinar ${ }^{5}$ entre as temáticas TICs, educação e cidadania. A relevância científica desta pesquisa centra-se na necessidade de debater tema de tamanha repercussão social, quanto a inclusão das TICs na educação, como meio ao desenvolvimento do exercício da cidadania.

Apesar da sociedade estar inserida no contexto digital, existe a necessidade de os profissionais envolvidos no processo de ensino desenvolverem competências para a inclusão das TICs. Por ser a escola um ambiente propício à introdução digital, a proposta é iniciar pelos professores, imigrantes digitais ${ }^{6}$ que, como tal, precisam se adaptar à realidade, em um movimento de desequilíbrio (do ponto de vista piagetiano), para que este seja o estopim no processo de reflexão sobre o papel das TICs, no exercício docente.

Com fundamento no exposto, o presente artigo está estruturado em três partes, trazendo inicialmente a contextualização a respeito dos conceitos centrais, essenciais a embasar e dar aporte teórico ao trabalho, seguido pela apresentação das metodologias e o relato de aplicação. Ainda, abarca a análise dos resultados, culminando com as considerações finais, na qual destaca-se o diálogo mediado pelas tecnologias digitais móveis e sua eficácia, nesse caso, à realização de reflexões.

\section{OS CAMINHOS PARA COMPREENDER A CONJUNTURA DO TEMA}

O ambiente escolar passa por constantes mudanças, premissa básica para os locais e objetos que sofrem influências dos seres humanos. Porém, nos últimos anos, com a vertiginosa evolução tecnológica, essas mudanças têm acontecido de maneira desenfreada. Tal fato vem ocasionando um distanciamento entre professores e alunos,

\footnotetext{
5 Segundo Fazenda (2011) o termo interdisciplinaridade não possui um sentido único, mas em sua concepção pode ser compreendido como a atitude dialógica de interação entre diversas disciplinas dentro de um mesmo projeto, que pressupõe a alteração do conhecimento fragmentado para o unitário.
} 
${ }^{6}$ É a pessoa que faz uso da internet e das tecnologias relacionadas, porém nasceu antes do advento da era digital (PALFREY; GASSER, 2011).

alunos e escola, surgindo assim, a necessidade de os profissionais da educação buscarem alternativas digitais, para intermediar essas transformações.

\subsection{As Tecnologias da Informação e da Comunicação na educação}

Em virtude do atual contexto histórico e social, vem a lume a possibilidade de utilização das TICs como política pedagógica no ambiente escolar, sendo assim, reconhecidas como meios para contribuir com a construção do conhecimento. Essas ferramentas podem proporcionar aos docentes novas perspectivas em sua prática pedagógica, além de facilitar a interação com discentes e colegas de trabalho.

Tais colocações ganham sentido a partir da concepção de Oliveira et al. (2015) ao afirmarem que as TICs referem-se as formas de tecnologias, ligadas a transmissão de informação mediada por processos de comunicação. Ainda, para esses autores, as TICs são um “[...] conjunto de recursos tecnológicos integrados entre si, que proporcionam por meio das funções de software e telecomunicações, a automação e comunicação dos processos de negócios, da pesquisa científica e de ensino e aprendizagem" (2015, p .77$78)$.

Diante o exposto, é imperioso destacar o papel da escola para a inserção das TICs, uma vez que, é função essencial desta instituição ofertar práticas formativas aos professores, para que tenham melhores condições de desenvolver seu potencial profissional. Além de, oferecer condições de incorporar as TICs em suas ações cotidianas, para que o façam, de modo inovador, em trabalhos colaborativos que propiciem a reflexão dos envolvidos no ambiente escolar (RODRIGUES et al., 2014).

Em razão disso, jamais pretendeu-se enaltecer as tecnologias como salvadoras, ou como solução para as mazelas da educação, pois em seu conceito "[...] a tecnologia serve para aprimorar a ação humana, otimizando, no caso na educação, a aprendizagem dos indivíduos" (PIROZZI, 2013, p.14). Urge, portanto, esclarecer que entre as TICs disponíveis no cenário brasileiro, há quantidade imensurável de recursos, que podem ser aplicados à realidade educacional e, para centrar esta pesquisa, foi eleito um recurso tecnológico específico, o aplicativo WhatsApp, definido por Gomes (2017) como um meio de comunicação instantâneo, através de mensagens de textos, imagens, vídeos, áudios e emoticons, disponível para uso em celulares e em versão para computadores.

Segundo o Instituto Brasileiro de Geografia e Estatística - IBGE na Pesquisa Nacional por Amostra de Domicílios Contínua - PNAD Contínua que abrangeu, no quarto trimestre de 2016, o tema suplementar TICs, dos mais de 116 mil brasileiros que utilizaram a internet neste período, o fizeram por meio do telefone móvel celular, o que corresponde a 94,6\% da população investigada. Ademais, em 38,6\% dos domicílios esse era o único meio de acessar a internet. Ainda neste levantamento, 94,2\% da população afirma que a principal finalidade dada ao acesso à internet é enviar ou receber mensagens de texto, voz ou imagem através de aplicativos diferentes de $e$-mail.

Os dados da pesquisa do IBGE (2016) ao referirem-se a aplicativos diferentes de e-mail, por esta terminologia, estavam direcionados à aplicativos como o WhatsApp. Esses são dados significativos, representam a conjuntura na qual a internet está inserida à realidade da população brasileira. A escola, por ser um espaço de interação humana, precisa acompanhar essas novas formas de comunicações.

Desta forma, isso é reforçado por Duvoisin et al. ao afirmarem que,

A comunicação tem sido, cada vez com mais intensidade, mediada pelas TIC, através da Internet, o que lhe confere um caráter expansivo, hipertextual e mais dinâmico. Essas novas formas de diálogo afetam a educação, pois a sociedade RENOTE 
convive diariamente com elas. Assim, é necessário problematizar e propor formas para que essa comunicação contribua com a construção do conhecimento e com o entendimento de diferentes realidades (2009, p. 02-03).

Com fulcro nesse parecer evidencia-se, mais uma vez, que a expansão da internet expõe a ligação intrínseca das TICs com a educação. Bem como, da problematização apresentada, surge a necessidade de adentrar na concepção de m-learning, para perceber suas potencialidades às práticas docentes.

As autoras Lima et al. (2014) introduzem a compreensão de m-learning, a partir da contextualização do exponencial crescimento das tecnologias móveis, desde as transformações no modo de agir e interagir das pessoas. Especificamente no que tange a educação, referem-se a esse termo como processos que fazem uso de dispositivos móveis e transmissão sem fio. Ainda ressaltam que o m-learning é apenas "[...] mais um recurso educacional e tecnológico que possibilita ao professor a melhoria da qualidade da educação [...] (LIMA et al., 2014, p. 434).

Considerações semelhantes são alcançadas por Boll e Melo (2014) que apresentam o m-learnig ou mobile learning como um modo de utilizar inovador e criativo de dispositivos móveis, como tablets e smartphones. Este tem como benefícios não se prender aos limites de espaço e tempo e ser acessado de qualquer lugar. Trata-se de uma ampliação das possibilidades dos processos de comunicação, em ambientes e com parâmetros de repercussão completamente diferenciados, com potencialidades e características extremamente úteis às realidades educacionais e socais brasileiras.

Dessa sorte, deve-se restar hialino que a inclusão das TICs na educação não significa a utilização de novos recursos para ensinar os conteúdos curriculares, ou a utilização de TICs para reproduzir técnicas tradicionais. Mas, uma forma de educar que vislumbra o desenvolvimento do senso crítico e as necessidades reais de um mundo que está em constante transformação (ADELL, 2012). Ou seja, é necessária uma educação de qualidade, que possibilite momentos de planejamento e reflexão dos professores, para que estes pautem sua prática em objetivos que propiciem a formação de cidadãos críticos.

\subsection{Imbricações entre a atividade docente e o fomento ao exercício da cidadania}

Questões vinculadas a temática deste estudo são amplamente discutidas por Demo (1995) ao sustentar que a educação de qualidade é uma política pública intrínseca à cidadania, pois favorece a equanimidade de oportunidades entre indivíduos de camadas sociais distintas. Porém, a educação não sustenta a cidadania de maneira automática, é necessária educação de qualidade formal ${ }^{7}$ e política ${ }^{8}$ para a formação de seres capazes de “[...] aprender a aprender, saber pensar, para melhor intervir" (DEMO, 1995, p. 146).

Neste contexto, a concepção de educação de qualidade adotada será a de Libâneo et al. (2010) ao entenderem que a concretização se dá no momento em que as instituições de ensino promovem, a todos, a posse do conhecimento e das habilidades cognitivas e afetivas, necessárias ao desenvolvimento dos anseios individuais e sociais dos discentes. Bem como, garantem a estes a composição da cidadania, como meio de inferir e participar na formação de uma sociedade mais equânime.

Ainda, para esses autores é preciso atentar que para uma educação de qualidade é indispensável compreender que "[...] escola não é fábrica, mas formação humana. Ela não pode ignorar o contexto político e econômico; no entanto, não pode estar subordinada ao modelo econômico e a serviço dele" (LIBÂNEO et al., 2010, p. 117).

\footnotetext{
${ }^{7}$ Está ligado a critérios econômicos e materiais (DEMO, 2012).

${ }^{8}$ Está ligado a critérios de formação humana para o pleno exercício da cidadania (DEMO, 2012).
} 
Nessa linha deve ser observada a necessidade de esclarecer aos docentes essas relações, para que possam compor sua conduta de modo condizente com suas atribuições. Visto sob este ângulo, seguem as contribuições de Borba e Penteado,

[...] uma visão mais ampla da educação deva subordiná-la à noção de cidadania e nossa posição é a de que devemos lutar para que a noção sobre o que é cidadão inclua os deveres e direitos não subordinados aos interesses apenas das grandes corporações. Então, se escola e empresa existem e fazem parte direta ou indiretamente das diversas sociedades complexas no mundo atual, não podemos pensar a escola como empresa, nem subordinar os interesses da primeira ao da segunda (BORBA; PENTEADO, 2016, p. 16-17).

Com o aventado, emerge a questão da educação de qualidade através da inclusão das TICs, nas quais o acesso à informática necessita ser um direito de todos. Assim, fazse necessário proporcionar aos indivíduos "alfabetização tecnológica", que não se trata de um curso, mas como aprender a perceber as mídias. Pois, o "[...] acesso a informática na educação deve ser visto não apenas como um direito, mas como parte de um projeto coletivo que prevê a democratização [...]" (BORBA; PENTEADO, 2016, p. 17).

De modo mais específico, a educação para ser emancipatória, na atualidade, precisa englobar capacitação tecnológica. Ou seja, que não se limita ao domínio da máquina no exercício do trabalho, mas que tenha competências suficientes para compreender a realidade, e também, aptidão para a cidadania e formação ética, oferecendo um alicerce à sociedade. Esses são alguns dos desafios pelos quais precisam passar os docentes no atual contexto histórico e social para exercer sua profissão (LIBÂNEO, 2011).

É evidente que se a capacitação à cidadania é uma barreira a ser enfrentada pelos docentes, estes precisam ter base para tanto. A definição que fundamenta este trabalho é de Carvalho (2008) que alberga o conceito de cidadão como aquele titular de direitos e deveres nas três esferas civil, política e social. Isto é, a construção da cidadania está ligada as relações estabelecidas entre as pessoas e o Estado, pois uma pessoa intitula-se cidadão de um Estado quando o reconhece como sua nação.

Segundo o autor o desenvolvimento desses direitos depende das peculiaridades de cada nação, não ocorrem de modo linear. Entretanto, destaca um ponto em comum nos países que alcançaram um avanço na cidadania, estes priorizaram o direito social a educação, que é pré-requisito à expansão de outros direitos. Destaca ainda, que a educação, por ser um direito social, tem o potencial de minimizar as desigualdades (CARVALHO, 2008). Ela pode trazer oportunidade para que os indivíduos percebam sua realidade, e assim tenham condições de realizar melhor suas escolhas.

Nessa mesma linha de pensamento Pinsky (2015) entende a cidadania não como algo abstrato, mas como uma ação prática, que manifesta uma consciência de pertencimento e de responsabilidade coletiva. É algo que não pode ser outorgado, precisa ser conquistado, por isso, o simples viver em um Estado Democrático não transforma todos em cidadãos. $\mathrm{O}$ autor apresenta como maneira de lutar por esse direito, o pensar sobre quais situações impedem seu exercício. Ademais, “[...] cabe a nós, educadores, um papel fundamental no sentido de ampliar o debate sobre a questão da cidadania e os limites impostos à sua prática" (PINSKY, 2015, p. 96).

Os três temas que perpassam por esse artigo são expressos em conjunto por Demo (2012) quando afirma ser o investimento em educação o mais eficiente meio de instrumentalizar a cidadania, além de promover o crescimento tecnológico. Esse foi o motivo de aproximação entre educação e tecnologia, porque educação traz desenvolvimento político, mas também desenvolvimento econômico, motivo pelo qual, atualmente, há um movimento de investimentos públicos em educação. A tecnologia é 
instrumento, enquanto a educação é o fim, e para se alcançar esse fim é necessário entender a tecnologia, o que impõe a educação estar em constante transformação.

Em suma, o tema abordado é complexo e visa a interdisciplinaridade, na busca por uma educação efetiva, a partir da conduta reflexiva dos docentes ao agirem em prol da formação de cidadãos críticos. Dessa sorte, resta cristalino a necessidade de pensar propostas que contribuam ao exercício da educação de qualidade, com momentos de interação e comunicação entre os integrantes do ambiente escolar, para que estes possam construir seus saberes.

\section{METODOLOGIAS DESENVOLVIDAS}

No que concerne a metodologia de pesquisa utilizada para o desenvolvimento deste trabalho, esta desenvolveu-se com base na metodologia bibliográfico documental, com abordagem qualitativa em caráter descritivo, fundada no relato e análise das experiências vivenciadas no PAE. Visto que, pela perspectiva de Trivinos (1987) a pesquisa qualitativa caracteriza-se pela escolha de um percurso que abarca a definição de um problema, coleta e análise das informações e culmina em esclarecimentos relevantes.

Outrossim, para embasar o planejamento e a prática do PAE foi eleita a metodologia educativa construtivista de Unidades de Aprendizagem (UA), pela identificação do potencial de protagonizar o desempenho dos integrantes do grupo e pelo estabelecimento de espaços de democratização do diálogo. Usou-se de temas contextualizados à realidade dos participantes, oportunizando momentos de pesquisa, reflexão, diálogo e reconstrução, como se poderá observar no relato da prática.

Nesta mesma tangente, contribuem Freschi e Ramos (2009) quando afirmam,

A finalidade da UA não é ensinar o professor a “dar” aulas ou a seguir receitas.
É um modo de organização do ensino no qual o professor reúne atividades para
que o aluno consiga relacioná-las com o conteúdo aprendido anteriormente,
dando significado a esses conteúdos (FRESCHI; RAMOS, 2009, p.158).

Deste modo, é possível crer que o essencial à aplicação dessa metodologia é ter cuidado na escolha das atividades que compõem a UA. Neste trabalho, tal característica se consolida pela atenção despendida na escolha dos recursos tecnológicos utilizados.

Com base nestas compreensões, foi utilizado como espaço virtual de registro, para a coleta das informações, o próprio grupo de WhatsApp, que armazenou e concentrou a comunicação entre os participantes. Alicerçado nestes diálogos desencadeou-se a análise descritiva dos debates e trocas de vivências.

\subsection{Relato da vivência}

A execução do PAE foi realizada com o grupo de docentes de uma escola no município de Gravataí/RS. Esta possui 24 professores nomeados, todos indivíduos do sexo feminino, entre 27 e 63 anos. Profissionais com formação desde o ensino médio/magistério à pós-graduação, com carga horária semanal de 20 à 60 horas. A aplicação do PAE ocorreu presencialmente e a distância, sendo que o encontro aconteceu nas dependências da escola em dia de formação continuada, iniciou-se por uma exposição oral e a explanação sobre a proposta do PAE, seguido por um debate sobre as TICs, com a apresentação de objetos de aprendizagem e ferramentas digitais.

Nesta ocasião, ocorreu o convite para participação voluntária em um grupo de WhatsApp, para dar continuidade aos debates do encontro presencial. Este formou-se por sete professores e a discussão desenvolveu-se durante as atividades a distância, com 
alicerce no que fora previamente problematizado. O grupo foi gerido pela pesquisadora, como mediador e, os voluntários foram instigados a realizar postagens, pesquisas e reflexões através de questionamentos, utilizando-se de recursos digitais. Foram empregados como gatilhos para abertura dos diálogos imagens, vídeos, links, charges, texto e perguntas. Conforme demonstrado no quadro a seguir:

Quadro 1 - Incidência de Recursos Motivacionais

\begin{tabular}{|l|l|}
\hline Recurso & Vezes utilizadas \\
\hline Perguntas & 8 \\
\hline Frases instigadoras & 2 \\
\hline Vídeos & 4 \\
\hline Infográfico & 1 \\
\hline Imagens & 2 \\
\hline Textos & 2 \\
\hline Áudios & 3 \\
\hline Planilhas & 1 \\
\hline Apresentações PowerPoint & 1 \\
\hline
\end{tabular}

Fonte: autora

Como pode-se observar, a pesquisadora, fez uso de diferentes recursos tecnológicos para motivar a interação, pois, o estudo teve por intuito observar o posicionamento dos docentes quanto aos temas. O próximo item discorre sobre a análise das publicações, ressaltando-se que essa ocorre exclusivamente por viés qualitativo.

\section{ANÁLISE DOS DADOS}

A partir do número restrito de professores voluntários é nítido que mesmo após primeiro contato presencial, houve resistência dos participantes para um debate mediado pelas TICs, por meio da utilização de grupo no WhatsApp. Percebe-se que se interessaram os profissionais com mais alto nível de formação. No tocante a faixa etária, observa-se uma proporcionalidade entre os voluntários e o número total de docentes da escola. Já que, entre a totalidade dos 24 professores, 18 têm menos de quarenta anos, e entre os sete que se disponibilizaram a participar, quatro também estão nesta faixa etária. Assim, notase que a idade não foi fator determinante.

No que concerne às falas, depreende-se que nem todos estavam dispostos a discutir o tema, ou não se sentiram motivados pelos recursos utilizados, já que, alguns participaram mais ativamente. Essa averiguação ocorreu por meio dos recursos oferecidos pela ferramenta WhatsApp, pois observou-se que todas as postagens da pesquisadora foram acessadas, inclusive com troca de postagens entre os próprios integrantes.

Posto que, segue trecho da fala de um dos professores, quanto a ligação das TICs à educação: [...] é necessária uma atualização na metodologia utilizada nas escolas $e$ não apenas de maneira superficial como a proposta pela prof da imagem. E, isso necessitará de um planejamento estratégico de formação continuada [...] (Professor 1). 
Da colocação alhures, destaca-se que parte do professor a conclusão pela necessidade de oferta de formação continuada, para que estes percebam sua prática e possam atualizá-la. Nesse sentido, Pimenta (1996) discorre sobre os nuances da formação da identidade do professor, ao compreender este processo como a necessidade de unir o conhecimento teórico à didática, um movimento de auto investigação pelos professores sobre sua prática, para construírem e transformarem seus saberes.

Em exame das publicações dos docentes é possível reuni-las em dois grandes grupos, o primeiro onde surgiram questões como: dificuldade de domínio/uso das TICs; necessidade de mudança de perspectiva pedagógica; escassez de recursos tecnológicos nas escolas; necessidade de formação continuada; reflexão sobre a descentralização do conhecimento. Não se pode olvidar, todavia, que esses pontos foram relatados por mais de um dos voluntários, temas que aparecem conectados à seguinte passagem de Moran,

\begin{abstract}
As tecnologias digitais móveis desafiam as instituições a sair do ensino tradicional em que o professor é o centro, para uma aprendizagem mais participativa e integrada, com momentos presenciais e outros com atividades a distância, mantendo vínculos pessoais e afetivos, estando juntos virtualmente. Podemos utilizar uma parte do tempo de aprendizagem com outras formas de aulas (2013, p.30).
\end{abstract}

Assim, nas palavras do autor, alguns aspectos apresentados pelos professores são contemplados, deve-se continuar pensando em como superar esses obstáculos. Neste sentido aventam Borba e Penteado (2016) ao trazerem as potencialidades do conflito, pois é em situações de perturbação que se está mais propenso às mudanças. Os desafios das tecnologias digitais às escolas devem ser vistos como um estímulo ao desenvolvimento. Trata-se de um duro percurso, é penoso mudar seu modo de operar, pode parecer mais fácil enquadrar as TICs a "velhas rotinas", mas é justamente o contrário que se espera dos professores, sendo necessários que saiam de sua zona de conforto.

O segundo agrupamento traz as seguintes questões: o papel importante realizado pelo professor; a falta de valorização da profissão na sociedade; a escola como ambiente de instrumentalização dos discentes para a vida; a dificuldade de dialogar com os pais; e a irresponsabilidade dos pais para com a educação dos filhos. Pode-se observar, nos apontamentos, a subjetividade de cada profissional, pois cada docente apresentou perspectivas distintas. Fundamentado na concepção de Demo (2012) são situações vinculadas ao desenvolvimento político que a educação pode desencadear na sociedade.

Os temas levantados nas postagens relacionam-se com o apontado por Libâneo ao reconhecer que a escola "[...] cumpre funções que não são providas por nenhuma outra instância [...]" (2011, p. 64), além de "[...] considerá-la como lugar onde os alunos aprendem a razão crítica para poderem atribuir significados às mensagens e informações recebidas das mídias [...]” (2011, p.65). Também, é preciso salientar, que os males causados pela desvalorização dos docentes apenas podem ser enfrentados com “[...] investimento social, que deverá ser referendado por toda a sociedade (que deverá se dispor a pagar o custo da opção)" (PINSKY, 2015, p. 109), pois como é sabido "o aumento de salário dos professores depende de vontade política de quem governa e de uma maior valorização da profissão pela sociedade em geral" (BORBA, PENTEADO, 2016, p. 14). Ambos são assuntos delicados que não podem passar desapercebidos quando se pretende conhecer os desafios encontrados pelos professores.

De maneira mais individualizada, destaca-se a fala de dois professores, quando discorrem a respeito das relações entre TICs, educação e cidadania, como observa-se,

É notório, e urgente, que a metodologia precisa mudar, tirar o foco no conteúdo e na testagem, valorizando o processo e autonomia discente. No 


\begin{abstract}
futuro não seremos mais conhecidos por "o professor que me ensinou”, mas pelo "professor que me ajudou a aprender". Acostumar-se com essa troca de papel leva tempo, mas deve ser igualmente gratificante para que as mudanças sejam realizadas. [...] ainda pensando em uma prática que provoque a autonomia dos educandos, deve-se a todo o momento instigar o posicionamento dos próprios alunos, para que a ética e a cidadania sejam construídas por cada sujeito. Para isso, saem as aulas expositivas, entram os debates, aulas participativas, com temas abertos, uso de novos dispositivos e tecnologias, metodologia flexível e trabalho interdisciplinar, o que na prática é mais oneroso que as tradicionais exposições e fórmulas (Professor 2).
\end{abstract}

Do mesmo modo, outro professor enfatiza,

[...] acredito que os profissionais da educação que ainda acreditam nela e trabalham com dedicação por ela, ainda podem continuar trabalhando sobre a formação de cidadãos críticos e éticos. Pois um governo é o reflexo da sociedade e a escola, por sua vez, é uma micro sociedade que possui as mesmas formas de relação existentes fora dela. Então o trabalho sobre a formação humana é ainda mais necessário do que as aprendizagens sobre os “conteúdos para o trabalho (Professor 3).

Com a análise das falas docentes, é crível que alguns alcançaram clareza dos objetivos deste estudo, o que desencadeia a crença na concretização da hipótese de desacomodá-los a pensar como utilizar as tecnologias no ambiente escolar para a reflexão sobre a cidadania. Outrossim, os mesmos demonstraram em suas postagens extremo senso crítico, ao destacarem que a escola é reflexo da sociedade e possui papel político para formação humana. Apontam que instigar o posicionamento emanado dos próprios discentes é o caminho para construir sua ética e cidadania.

De igual forma, ponto de vista pertinente é apresentado em um dos comentários, conforme segue [...] a tecnologia vem para otimizar o tempo do professor, gestor, supervisor... auxiliando de maneira eficaz a comunicação entre os segmentos da escola, além de transcender os muros da escola. (Professor 2). Depreende-se do posicionamento desse professor sua percepção sobre o tema que emerge de modo implícito a este estudo, ou seja, o uso das TICs como meio de potencializar os espaços de debates entre os docentes. Por seu turno, tal questão é observada em outros estudos como o de Duvoisin et al. (2009) que coloca a utilização das TICs como meio de minimizar as distâncias, através da conversa pela leitura e escrita intermediada pelas tecnologias. Com a análise, ora realizada, percebeu-se que inúmeros são os entraves enfrentados pelos docentes na atividade profissional, e que o espaço de debate no aplicativo WhatsApp pode proporcionar a reflexão sobre os temas propostos segundo sua realidade.

\title{
CONSIDERAÇÕES FINAIS
}

Em decorrência do exposto, é possível observar na análise das falas docentes, que estes percebem os desafios enfrentados cotidianamente, pois reconhecem o quanto é trabalhoso se reinventar. Pensar em como trazer para dentro das escolas as TICs, sem receber o devido aporte de recursos físicos, financeiros e de formação, não os deixa em zona de segurança. Contudo, observar que os professores reconhecem esses entraves e continuam em sua batalha diária em prol da formação humana dos discentes, é o essencial.

Convém acrescentar, que da análise dos resultados, veio à ebulição o tema conversa pela escrita mediada por tecnologias digitais móveis, e suas potencialidades em dirimir os limites de espaço/tempo, para a troca de vivências entre os professores. Com essa forma de interação houve reflexão de qualidade, e os ganhos possibilitados foram consideráveis, visto que, semeou-se o pensar sobre essa temática entre os professores. 
Os momentos de diálogos viabilizaram a percepção da situação de crise em que encontra-se a educação ao buscar meios de incorporar as tecnologias no cotidiano. No entanto, academicamente, resta factível que a crise é algo positivo, pois é a partir dela que as mudanças ocorrem. Para além dessa certeza, sobressai a crença na responsabilidade da escola e do professor em buscar educação de qualidade que propicie a minimização das desigualdades sociais. Entretanto, entende-se que os professores não precisam sentir-se ameaçados pelas tecnologias, pelo contrário, devem fazer uso das TICs para otimizar seu trabalho e assim instrumentalizar seus discentes para conseguir ler a realidade do mundo em que estão inseridos e agir criticamente sobre ele. Sem dúvida, este tema não tem a devida atenção no cenário educacional brasileiro, é apenas uma palavra bonita utilizada como manobra política em ações de governo, quando deveria ser objeto de políticas públicas de Estado, propostas a longo prazo, para assim, ter a repercussão necessária.

\section{REFERÊNCIAS}

ADELL, Jordi. Educaç ão 2.0. In.: BARBA, Carme; CAPELLA, Sebastià. (Org.)

Computadores em Sala de Aula: métodos e usos. Porto Alegre: Penso, 2012, p. 25-38.

BOLL, Cíntia Inês; MELO, Rafaela da Silva. Cultura digital e educação: desafios contemporâneos para a aprendizagem escolar em tempos de dispositivos móveis.

CINTED-UFRGS. Novas tecnologias na educação. v. 12, n. 1, 2014. Disponível em: < http://goo.gl/baKWvw>. Acesso em: 28 jun. 2018.

BORBA, Marcelo de Carvalho; PENTEADO, Miriam Godoy. Informática e educação matemática. 5. ed. Belo Horizonte: Autêntica, 2016.

CARVALHO, José Murilo de. Cidadania no Brasil: o longo caminho. 10. ed. Rio de Janeiro: Civilização Brasileira, 2008.

DEMO, Pedro. Desafios modernos da educação. 18. ed. Petrópolis: Vozes, 2012.

. Cidadania tutelada e cidadania assistida. Campinas: Autores associados, 1995.

DUVOISIN, Ivane Almeida; VANIEL, Berenice Vahl; MOURA, Ana Carolina de Oliveira Salgueiro de; LAURINO, Débora Pereira. Conversar pela escrita: possibilidades de aprendizagens na educação a distância. In.: Encontro Internacional do Sistema Universidade Aberta do Brasil. Brasília, 23, 24 e 25 de novembro de 2009.

FAZENDA, Ivani Catarina Arantes. Integração e interdisciplinaridade no ensino brasileiro: efetividade ou ideologia. São Paulo: Edições Loyola, 2011.

FRESCHI, Márcio; RAMOS, Maurivan Güntzel. Unidade de Aprendizagem: um processo em construção que possibilita o trânsito entre senso comum e conhecimento científico. Revista Electrónica de Enseñanza de las Ciencias. v. 8, n. 1, 2009, p. 156170. Disponível em: 〈goo.gl/EHNRjF〉. Acesso em: 18 jun. 2018.

GOMES, Vânia Amaro. WhatsApp em sala de aula: comunicação docente e discente. 2017. 127 f. Dissertação (Mestrado em Ciências Humanas) - Universidade de Santo 
Amaro, São Paulo, 2017. Disponível em: <goo.gl/V2CR5C>. Acesso em: 12 maio 2018.

IBGE. Pesquisa Nacional por Amostra de Domicílios Contínua. Diretoria de pesquisa, 2016. Disponível em: <goo.gl/CuHXZr>. Acesso em: 13 maio 2018.

LIBÂNEO, José Carlos; OLIVEIRA, João Ferreira de; TOSCHI, Mirza Seabra. Educação escolar: políticas, estrutura e organização. 9. ed. São Paulo: Cortez, 2010.

LIBÂNEO, José Carlos. Adeus professor, adeus professora?: novas exigências educacionais e profissão docente. 13. ed. São Paulo: Cortez, 2011.

LIMA, Patricia Roseane Borges de; FALKEMBACH, Gilse Antoninha Morgental; TAROUCO, Liane Margarida Rockenbach. Objetos de aprendizagem no contexto de mlearning. In.: TAROUCO, Liane Margarida Rockenbach; ÁVILA, Bárbara Gorziza; SANTOS, Edson Felix dos; BEZ, Marta Rosecler; COSTA, Valeria. (Org.) Objetos de aprendizagem: teoria e prática. Porto Alegre: Evangraf, 2014, p. 431-447.

MORAN, José Manuel. Desafios que as tecnologias digitais nos trazem. In.: MORAN, José Manuel; MASETTO, Marcos T.; BEHRENS, Marilda Aparecida. Novas tecnologias e mediação pedagógica. 21. ed. Campinas: Papirus, 2013.

OLIVEIRA, Claúdio de; MOURA, Samuel Pedroso; SOUSA, Edinaldo Ribeiro de. TIC'S na educação: a utilização das tecnologias da informação e comunicação na aprendizagem do aluno. Revista Pedagogia em Ação. v. 7, n. 1, 2015, p. 75-95. Disponível em: <goo.gl/vTFq1K>. Acesso em: 20 abr. 2018.

PALFREY, John; GASSER, Urs. Nascidos na era digital: entendendo a primeira geração de nativos digitais. Porto Alegre: Grupo A, 2011.

PIMENTA, Selma Garrido. Formação de professores: saberes da docência e identidade do professor. Rev. Fac. Educ. [online]. v. 22, n. 2, 1996, p. 72-89. Disponível em: <goo.gl/1UxuWR>. Acesso em: 13 maio de 2018.

PINSKY, Jaime. Cidadania e educação. 10. ed. São Paulo: Contexto, 2015.

PIROZZI, Giani Peres. Tecnologia ou Metodologia? O grande desafio para o século XXI. Revista Pitágoras, Nova Andradina, v. 4, n. 4, dez/mar. 2013, p. 1-19. Disponível em: <goo.gl/Bc2d8m>. Acesso em: 28 jun. 2018.

RODRIGUES, Herik zednik; TAROUCO, Liane Margarida Rockenbach; KLERING, Luis Roque. Incorporação das TIC à gestão escolar e à prática pedagógica: indicadores para o desenvolvimento do e-Maturity. In.: SILVA, Maria Beatriz Gomes da; FLORES, Maria Luiza Rodrigues. (org.) Formação a distância para gestores da educação básica: olhares sobre uma experiência no Rio Grande do Sul. Porto Alegre: Evangraf, 2014, p. 21-51.

TRIVINOS, Augusto Nibaldo Silva. Introdução à pesquisa em ciências sociais: a pesquisa qualitativa na educação. São Paulo: Atlas, 1987. 